\title{
Safety and security of Japanese society threatened by unpredictable earthquake and tsunami: overcoming the crisis with Japanese wisdom and cheer
}

\author{
Masaaki Hosomi
}

Published online: 1 June 2011

(C) Springer-Verlag 2011

Was this happening in reality? What a catastrophe it was. It seems like we are still having the worst nightmare.

The great East Japan earthquake of magnitude 9.0 that struck at 14:46 h on 11th of March 2011 was the world's fourth largest. The unprecedented and unpredictableSOUTEIGAI-monster earthquake led to a subsequent gigantic tsunami-one of the SOUTEIGAI aftermathswhich devastated towns and villages along the coastline of Pacific Ocean. One prominent example is the collapse of the world's deepest tsunami protection breakwater. The breakwater, located at the mouth of Kamaishi bay, Iwate Prefecture in northern Japan, was proclaimed by Guinness Book of World Records in July 2010 as the world's deepest breakwater (63 m deep) embedded in the bottom of the sea. It was a large-scale caisson breakwater and was designed against a massive earthquake and resultant tsunami. It took 31 years to complete the construction (completed in March 2009) at a cost of 126 billion Japanese yen (1.5 billion US\$). The breakwater had a $1960 \mathrm{~m}$ length and the base was located at $63 \mathrm{~m}$ beneath the seawater surface. It was not affected when receiving the $2 \mathrm{~m}$ high tsunami derived from the gigantic earthquake in Chile on 27th of February 2010. However, it failed to stop the tsunami this time. Other breakwaters were also devastated by the tsunami. The breakwater with length and height of 2,430 and $10 \mathrm{~m}$, respectively, constructed on land in Miyako (Iwate Prefecture), is named Great Wall of China after its appearance. The tsunami easily surmounted the breakwater, which claimed a lot of lives. Presumably, the height of the

M. Hosomi ( $\square)$

Department of Chemical Engineering, Tokyo University

of Agriculture and Technology, 2-24-16 Nakamachi,

Koganei, Tokyo 184-8588, Japan

e-mail: hosomi@cc.tuat.ac.jp tsunami in Miyako was more than $15 \mathrm{~m}$. Three hundred kilometers of coastline of the quake-stricken areas has been protected by breakwaters but two-thirds of the breakwaters were completely or severely devastated.

Above all, the issue people all over the world have been concerned about is the status of the Fukushima I Nuclear Power Plant comprising of six atomic power reactors (total electric generation capacity of 4.7 million kilowatts). The power plant is located on the coastline of the Pacific Ocean in Fukushima Prefecture. In order to protect tsunamis, the $5.5 \mathrm{~m}$ high breakwater was constructed in 1979. However, the more than 14-m-tsunami blasted the power plant. Consequently, the reactors were urgently halted after the earthquakes; however, the cooling system, which is supposed to cool the reactors down by circulating water, did not function because of blackout. This is because the unpredicted-SOUTEIGAI-tsunami broke down emergency diesel power generators, resulting in another SOUTEIGAI aftermath. The prime minister Naoto Kan declared a nuclear emergency situation and ordered residents within $3 \mathrm{~km}$ away from Fukushima I Nuclear Power Plant to evacuate. The next day, the concrete wall covering the atomic power reactor 1 was blasted due to accumulation of hydrogen. The nuclear rods were severely damaged and radioactive cesium was detected. For now, cooling operation has been attempted but high concentration of radio active compounds prevents workers to restore the operational system.

Radioiodine 131 was detected in the atmosphere around the power plant. Even in the Tokyo region, $250 \mathrm{~km}$ away from the power plant, a level of radioactivity in the atmosphere has been twice as high as normal. Radioactive compounds were detected in some vegetables grown near the power plant; therefore, their shipment is currently halted. Radioactivity was detected even in drinking water 
facilities in Tokyo and as was the case for seawater adjacent to the power plant. Apprehension of release of radioactive compounds is growing not only in the atmosphere but also in aquatic resources.

In sum, the unpredictable, or SOUTEIGAI, gigantic earthquake and resultant tsunami brought cascading accidents in the nuclear power plant, which boasted having a multiple fail-safe system. Japan is currently facing inconceivable crisis of survival. We have to scratch our heads and assemble our wisdom in order to overcome this crisis. Cheers for Japan! 